\title{
Reasons for Delayed Breastfeeding Initiation among Newly Delivered Women in Two First-Category Hospitals in Yaoundé, Cameroon
}

\author{
Félicitée Nguefack ${ }^{1,2 *}$, Dany Hermann Ngwanou1, Georges Pius Kamsu Moyo¹, Louise Ejake1, \\ Evelyn Mungyeh Mah',2, Guy Wafeu1, Danny Stève Fodoung Wamba ${ }^{3}$, Andreas Chiabi1,2
}

\author{
${ }^{1}$ Faculty of Medicine and Biomedicals Sciences, University of Yaoundé 1, Yaoundé, Cameroon \\ ${ }^{2}$ Yaoundé Gynaeco-Obstetric and Pediatric Hospital, Yaoundé, Cameroon \\ ${ }^{3}$ Faculty of Health Sciences, University of Bamenda, Bamenda, Cameroon \\ Email: ^dongfel@yahoo.fr
}

How to cite this paper: Nguefack, F., Ngwanou, D.H., Kamsu Moyo, G.P., Ejake, L., Mah, E.M., Wafeu, G., Fodoung Wamba, D.S. and Chiabi, A. (2020) Reasons for Delayed Breastfeeding Initiation among Newly Delivered Women in Two First-Category Hospitals in Yaoundé, Cameroon. Open Journal of Pediatrics, 10, 474-485. https://doi.org/10.4236/ojped.2020.103048

Received: June 5, 2020

Accepted: September 5, 2020

Published: September 8, 2020

Copyright $\odot 2020$ by author(s) and Scientific Research Publishing Inc. This work is licensed under the Creative Commons Attribution International License (CC BY 4.0).

http://creativecommons.org/licenses/by/4.0/

\begin{abstract}
Introduction: Exclusive breastfeeding is fundamental for the good health and development of the mother and the child. According to the World Health Organization (WHO), breastfeeding after childbirth should be initiated within 30 minutes. For a number of reasons, WHO recommendations on guiding principles for infants and young children feeding are often not followed. Objective: To determine the reasons for the delayed initiation of breastfeeding in newly delivered women. Means and Method: We carried out a mixed cross-sectional study over a period of six months from December $1^{\text {st }} 2018$ to May $31^{\text {st }} 2019$, at the Yaoundé Gynaeco-Obstetric and Pediatric Hospital. We included all mothers with full-term or premature babies weighing $\geq 2000$ grams and those whom initiated breastfeeding more than one hour after delivery. The mother's reasons for delaying breastfeeding initiation were recorded using a dictaphone and data were accurately extracted for analysis. Results: We interviewed 153 mothers. Their mean age was $27.9 \pm 6.2$ years. The main reasons for delaying breastfeeding initiation were caesarean delivery $(22 \%)$, the belief in "spoiled milk" (21\%), lack of knowledge about the time to initiate breastfeeding (21\%), baby asleep (18\%), and lack of instruction given to the mother by the health staff (2\%). Conclusion: Delayed breastfeeding was common in our context. Improving the quality of breastfeeding involves communication, to break beliefs about spoiled milk, and strengthening mothers' knowledge for optimal breastfeeding processes in accordance with WHO's guidelines. The medical staff should anticipate and
\end{abstract}


undertake the early initiation of breastfeeding in babies from mothers who deliver through caesarean section.

\section{Keywords}

Childbirth, Breastfeeding, Delay, Reasons, Yaoundé

\section{Introduction}

The early initiation of breastfeeding (EIBF), or timely initiation of breastfeeding, may be defined as the starting of breastfeeding within the first hour following of childbirth [1]. According to the WHO, breastfeeding should take place within 30 minutes or an hour after childbirth [2] [3]. EIBF practice in low and middle-income countries is relatively higher than in developed countries [4]. Breastfeeding has been accepted as the easiest, effective and most successful intervention for the good physical and mental health of children [2] [5] [6] [7]. Recent studies in Ethiopia, Ghana, Bolivia and Madagascar found that breastfeeding could prevent up to $20 \%-22 \%$ of neonatal deaths [6] [7] [8]. In these countries, the average time for early breastfeeding initiation could reach up to an hour after delivery, but varied within this timeframe from one study to another. This rate was more than 70\% in France and Canada in 2016 [9], 68.7\% in Iran in 2016 [10] and 83.7\% in Ethiopia in 2017 [11]. In the literature, numerous reasons have been put forward as possible explanations for the delay in breastfeeding, among which: the lack of knowledge of the nursing staff and mothers, the geographical origin of mothers, and delivery by caesarean section, just to name a few [9] [11] [12] [13]. In India in the year 2017, the reasons recorded from health workers were: the lack of knowledge about breastfeeding techniques, breast anomalies, obstetric and neonatal complications and cultural practices [12]. In Cameroon, according to observations made during our daily practice, the initiation of breastfeeding at birth seems to be long. However, there is scarcity of data in our context concerning the reason for this delay. This justifies the present study whose outcome may contribute to reinforce public health actions in the light of the results, in order to enhance the reduction of maternal and infant morbidity and mortality in Cameroon.

\section{Means and Method}

We conducted a mixed cross-sectional study with prospective data collection, over a six-month period from December $1^{\text {st }}, 2018$ to May $31^{\text {st }}, 2019$, in the gynecology and obstetrics departments of the Yaoundé Gynaeco-Obstetric and Pediatric Hospital, which is a referral and Teaching Hospital in Cameroon. We included all mothers of full-term or premature newborns weighing at least 2000 grams, who agreed to participate. Mothers with contraindications to breastfeeding and those with newborns presenting emergencies that needed urgent man- 
agement at birth, such as major digestive malformation, and neurologic problems with feeding disorders were excluded. As well as Mothers who chose mixed feeding including breastmilk and formula. Whereas, mothers who had initiated breastfeeding more than one hour after delivery were enrolled. The questionnaire was pretested at the maternity service of another hospital in Yaoundé, with standards similar to our study site. This permitted us to correct misunderstandings and complete information necessary for the reliability of the questionnaire, before its use. The questionnaire was then administered by three researchers among the authors of this research study. The sampling procedure was consecutive. The variables recorded were: age, occupation, level of education, region of origin, marital status. The reasons for breastfeeding delay were sought during an inclusive interview, in the course of which mothers could express themselves freely. We submitted the questionnaires to mothers individually. A Dictaphone was used to record the interviews. We analyzed the records and translated them in English. The analyses continued throughout the discussions as newly emerging themes were tested in subsequent discussions. Hence, the initial analysis was inductive and followed by the preparation of the utilization model to enhance the robustness of the emerged domain. Other variables collected in the questionnaire included socio-demographic characteristics of the mothers. The data pertaining to reasons evoked for delaying breastfeeding initiation were faithfully extracted for analysis after grouping them into four categories. These reasons were either related to mothers, the newborns, the medical staff or socio-cultural issues. Quantitative data were entered and analyzed using CS Pro version 6.2 software and SPSS version 20.0. Chi-square testing was used to establish statistical associations between the variables. Qualitative variables were integrated into a simple logistic regression model to determine the Odd Ratio. A p-value < 0.05 was considered statistically significant for all analyzes.

We defined early initiation of breastfeeding as the starting of breastfeeding within the first hour following childbirth. The newborn might have been clothed or not, skin-to-skin contact was however recommended in our context. Delayed breastfeeding was considered as the initiation of breastfeeding after the first hour of life.

\section{Ethical Considerations}

Ethical clearances from the Institutional Ethics and Research Committee of the Faculty of Medicine of the University of Yaoundé 1 and the Yaoundé Gynaeco-Obstetric and Pediatric Hospital were obtained before the beginning of the study. The data collected was kept strictly confidential and used only for the purposes of the study.

\section{Results}

We interviewed 153 mothers who had put their baby to the breast beyond the first hour of life. 


\subsection{Socio-Demographic Data}

The mothers had an average age of $27.9 \pm 6.2$ years, and most of them originated from the Centre region (44.40\%), and had secondary education level (43\%) (Table 1).

\subsection{Reasons for the Delay of Breastfeeding Initiation}

The same mother could mention several reasons (Table 2).

\subsubsection{Mother-Related Reasons}

\section{- Caesarean delivery}

The majority of mothers who had a delay in breastfeeding initiation linked it to caesarean delivery (22.0\%), although some (38.0\%) had an acceptable milk flow, this reason was most of the time revealed by those who were not counseled. For example, half of them said, "I didn't know that the baby was supposed to be put to the breast immediately, even after the caesarean delivery". Some mothers' reports were: "I thought that the effect of the anesthetic drugs should pass first before putting the baby to the breast"; others responded "I was afraid that the anesthetics would pass into the milk and cause my baby a worry".

Table 1. Summary of sociodemographic data.

\begin{tabular}{|c|c|c|}
\hline Variables & Number & Percentage (\%) \\
\hline \multicolumn{3}{|l|}{ Age range (years) } \\
\hline$<20$ & 18 & 7.2 \\
\hline$[20-30]$ & 132 & 52.8 \\
\hline$[30-40]$ & 89 & 35.6 \\
\hline$>40$ & 11 & 4.4 \\
\hline \multicolumn{3}{|l|}{ Occupation } \\
\hline Housewife & 97 & 38.8 \\
\hline Civil servant & 43 & 17.2 \\
\hline Student & 38 & 15.2 \\
\hline Others & 72 & 28.8 \\
\hline \multicolumn{3}{|c|}{ Region of origin $(n=248)$} \\
\hline Centre & 110 & 44.6 \\
\hline West & 68 & 27.2 \\
\hline Others & 72 & 28.2 \\
\hline \multicolumn{3}{|c|}{ Level of education } \\
\hline Out-of-school & 14 & 5.6 \\
\hline Primary & 28 & 11.2 \\
\hline Secondary & 107 & 42.8 \\
\hline University & 101 & 40.4 \\
\hline
\end{tabular}


Table 2. Summary of reasons given by the mothers to with regard of the delay in breastfeeding initiation.

\begin{tabular}{cccc}
\hline $\begin{array}{c}\text { Related conditions to } \\
\text { breastfeeding delay }\end{array}$ & Reasons & Number & (\%) \\
\hline & Delivery by ceasarean section & 55 & 22.0 \\
Ignorance & 51 & 20.4 \\
Mother & No milk production & 23 & 9.2 \\
& Mother's refusal & 21 & 8.4 \\
Ill mother & Nipple anomalies & 17 & 8.0 \\
Health care provider & Lack of advice to the mother & 9 & 0.8 \\
& Wrong advice to the mother & 2 & 3.6 \\
Newborn & Ill or hospitalized baby & 19 & 0.8 \\
& Sleeping baby & 13 & 7.6 \\
\hline Socio-cultural beliefs & "Spoiled milk" & 40 & 16.0 \\
& Death of a baby due to breastfeeding & 9 & 3.6 \\
\hline
\end{tabular}

\section{- Ignorance about the time of breastfeeding initiation}

Ignorance (20.4\%) was very often recorded in combination with other reasons. For example, some women said: "I never knew that the baby should be put to the breast within an hour after delivery". Some respondents linked the recommended breastfeeding time to the death of their infant, and this is a cultural belief in some localities. They responded "My first baby was breastfed early and died"; other mothers attached to common practices argued "I usually give to my babies formula first until I am well enough to breastfeed them", or "I always give to my babies formula first after delivery".

\section{- No milk production}

This reason was very often related to unawareness, as these mothers did not know that lactation could also be influenced by breastfeeding. Some would wait for the milk secretion to be effective before putting the baby to the breast: " $I$ would wait until the milk starts to flow before putting the baby to the breast, otherwise if I put the baby to the breast, it would get angry and cry even more". "And in the meantime I would give water/ milk..." responded some women.

\section{- Mother's refusal}

Some mothers (8.4\%) refused to put the baby early on to the breast, for a variety of reasons: to avoid breasts damage, some responded "when I breastfeed the baby, my breasts will fall off...", some other women, because they were working mothers argued " $P \mathrm{~m}$ going to go out to work anyway so there's no need to put the baby to the breast now and then stopping when I go back to work". Mothers who chose infants formula for medically proven reasons were also in- 
cluded in this category.

\section{- Ill mother}

Some mothers (8.0\%) were hospitalized in the intensive care unit for postpartum complications such as eclampsia, postpartum hemorrhage which contributed to further delaying early breastfeeding initiation. Close to $6 \%$ of women evoked illnesses such as hemorrhage and infection, while extreme fatigue and asthenia were evoked by $2 \%$ mothers. Others health conditions such as perineal lesions, pelvic pain, headaches, cramps or myalgia were reported by a number of women too. Indeed, they felt they were not "healthy" and declared "they could contaminate the baby with illness if they put them to the breast".

\section{- Newborn-related reasons}

Some mothers (7.6\%) felt, despite the recommendations of the medical staff, that breastmilk could worsen the health condition of the hospitalized newborn, whereas their condition did not contraindicate breastfeeding. One-third of such neonates effectively had conditions such as respiratory distress, prematurity or severe malformations that contraindicated breastfeeding.

\section{- Sleeping baby}

In such situations, a number of mothers were waiting for the baby wake-up before initiating breastfeeding and some of them declared: "When the baby sleeps like this, I too can rest and breathe a little before putting him to the breast".

\subsubsection{Reasons Related to Health Care Providers}

This was about instructions given to the mother by health care provider. Indeed, $3.6 \%$ of the mothers revealed that they had never received any instructions from the health personnel concerning the early initiation of breastfeeding. Meanwhile, $2.3 \%$ had been advised to stop worrying about breastfeeding, because there was no problem to delay its initiation, the reason being that the newborn has reserves that can hold until it is put to the breast, even if this was done later on. Some mothers (3.2\%) with infectious diseases like HIV, hepatitis, were instructed to never breastfeed their baby.

\subsubsection{Socio-Cultural Reasons}

This concerned the "spoiled milk" issue, with almost $16.0 \%$ of mothers believing that their breastmilk was a danger for their newborn. Among these mothers with such beliefs, 3.6\% had lost children and thought it was because of breastfeeding.

\section{Discussion}

The main limit of this survey is the fact that all possible descriptive analyses that can be made from this study could have deeper considerations when proved by analytical assessments with the establishment of relationships, between delayed breastfeeding initiation and various supposed determinants. Thus future studies could be dedicated to the assessment of the factors determining the EIBF in our context. 
Looking at the various reasons evoked by women enrolled for delaying breastfeeding initiation, we grouped the reasons into four main items including those pertaining to maternal unavailability, neonatal unavailability, the lack of information and the respect of caregivers' instructions. These various motifs recorded in our survey, could have also negatively impacted the Early Initiation of Breastfeeding (EIBF), with a rate of $40 \%$ reported in the national demographic health survey in our country [14]. This rate is quite lower than those reported from a number of developing African countries such as in North West Ethiopia (73.1\%) and in Rural Kenya (76\%) [11] [15]. Indeed, when the newborn is not breastfed within 24 hours after birth, there is a significant risk that it may receive other fluids instead of breastmilk. This may eventually have repercussion on the rate of exclusive breastfeeding, which remains low $(20 \%-28 \%)$ in different surveys in Cameroon [16] [17] [18].

Maternal indisposition was mainly due to caesarean section delivery, which contributed for about $22.0 \%$ of women with delayed breastfeeding. Cesarean section is a known determinant for the delay of breastfeeding initiation, described by a number of researchers in various contexts [19] [20]. Hormones variations after caesarean section including the drop of endorphin, prolactin, and oxytocin blood levels have been incriminated for reducing galactorrhea and the desire to breastfeed during the immediate post-operative period [21]. If we admit an optimal rate of caesarean deliveries around $15 \%$ in our context, it may imply that, in the absence of considerable efforts to encourage breastfeeding, almost $15 \%$ of mothers will not initiate breastfeeding within the first hour after delivery. This mode of childbirth should not be an excuse for delaying breastfeeding initiation, especially in our limited-resource context, where health care is enormously expensive and cost-worthy. In such situations, anticipatory measures are recommended to promote breastfeeding within the time limit [22]. Close to $6 \%$ of women evoked illnesses such as hemorrhage, and infection, while extreme fatigue and asthenia were listed by $2 \%$ of non-breastfeeding women, making them unfit during the first hours following delivery. Complications involving women's breasts such as engorgement, inverted nipples, agalactorrhea were evoked by more than $1.5 \%$ of women with delayed breastfeeding due to pain and milk-flow obstruction [3] [23].

The newborns unavailability for early breastfeeding initiation according to mothers was mainly due to conditions such as neonatal infection, and low birthweight. However, these motifs were likely fallacious, given that newborns recruited in this survey had weights $\geq 2000$ grams. Moreover, infection or sepsis is neither an absolute contraindication to early breastfeeding initiation. Furthermore, most pathological conditions in neonates may generally not present immediately after birth. This supposes that mothers usually have enough time to initiate breastfeeding before any complications occur. This factor had been earlier described by a number of authors, and seemed to be true in women enrolled in our survey, occurring in more than $7 \%$ of them [23] [24] [25]. 
Some Authors demonstrated that vaginal delivery and maternal knowledge of correct breastfeeding practices were associated in early breastfeeding initiation in up to $87.0 \%$ of mothers [26]. The lack of information may therefore account as well among the main reasons for the late initiation of breastfeeding. We found that up to $20.4 \%$ of the mothers interviewed, were unaware of the concept of early breastfeeding initiation, and so they could therefore not apply it. The lack of knowledge in our context may be due to the health system that fails to provide enough counselling on infant feeding to women [27]. There is a necessity to reach women and assist them throughout pregnancy, delivery and postpartum by skilled practitioners for reliable counseling and necessary interventions where need be [3] [11]. In Nigeria, the social support during childbirth has catalyzed the early breastfeeding initiation especially for first-time mothers [28]. In the present study, $3.6 \%$ of women with delayed breastfeeding mentioned that they had respected instruction given by the attending medical staff. This could reflect the lack of training or qualification of some delivery room staff on breastfeeding. Furthermore, the low level of information was reinforced by socio-cultural believes such as the "spoiled or bad milk" concept in reference to colostrum, and the fear of "breast sagging", which all led to breastfeeding refusal in more than $8 \%$ of these women. Women with initial agalactorrhea were less receptive to the demand of continuous stimulation through repeated baby suckling of the breast, because of limited knowledge and misunderstandings [12] [23]. This wrong belief is frequently encountered in Cameroon, particularly in the Centre region, where some women rely on the fact that "their milk would be spoiled and not worthy to be given to their babies at the risk of "harming or even killing them". These mothers generally refer to a previous death of a newborn who had been breastfed, and unfortunately link this death to the early intake of breastmilk. However, in addition to being a cause of delayed breastfeeding initiation, false beliefs in the long term may lead to a total absence of breastfeeding with all the complications that can result from it [29].

\section{Conclusion}

Despite the WHO recommendations and its innumerable benefits [30], the delay in initiating breastfeeding at birth is a glaring reality in our context. It is crucial that health care providers reinforce efficient interventions by encouraging skin-to-skin contact between mother and newborn immediately after birth in order to take advantage of the early initiation of breastfeeding. Particular emphasis should be placed on supporting mothers who give birth through caesarean section and mothers from the Centre region of our country who strongly believe in the theory of "spoiled milk". This also requires individual communication by trained health workers on breastfeeding directives.

\section{Acknowledgements}

Hospitals authorities, all collaborators to this project. 


\section{Funding}

Private.

\section{Conflict of Interest}

The authors declare that they have competing interest.

\section{References}

[1] Beyene, M.G., Geda, N.R., Habtewold, T.D. and Assen, Z.M. (2017) Early Initiation of Breastfeeding among Mothers of Children under the Age of 24 Months in Southern Ethiopia. International Breastfeeding Journal, 12, Article No. 1. https://doi.org/10.1186/s13006-016-0096-3

[2] World Health Organization (2000) Effect of Breastfeeding on Infant and Child Mortality Due to Infectious Diseases in Less Developed Countries: A Pooled Analysis. WHO Collaborative Study Team on the Role of Breastfeeding on the Prevention of Infant Mortality. The Lancet, 355, 451-455. https://doi.org/10.1016/S0140-6736(00)82011-5

[3] Victora, C., Sankar, M., Rollins, N., Murch, S., Krasevec, J., Horton, S., et al. (2016) Breastfeeding in the 21st Century: Epidemiology, Mechanisms, and Lifelong Effect. The Lancet, 387, 475-490. https://doi.org/10.1016/S0140-6736(15)01024-7

[4] Patel, A., Bucher, S., Pusdekar, Y., Esamai, F., Krebs, N., Goudar, S., et al. (2015) Rates and Determinants of Early Initiation of Breastfeeding and Exclusive Breast Feeding at 42 Days Postnatal in Six Low and Middle-Income Countries: A Prospective Cohort Study. Reproductive Health, 12, Article No. S10. https://doi.org/10.1186/1742-4755-12-S2-S10

[5] Mullany, L.C., Katz, J., Li, Y.M., Khatry, S., LeClerq, S., Darmstadt, G.L. and Tielsch, J.M. (2008) Breast-Feeding Patterns, Time to Initiation, and Mortality Risk among Newborns in Southern Nepal. The Journal of Nutrition, 138, 599-603. https://doi.org/10.1093/jn/138.3.599

[6] Baker, E., Sanei, L. and Franklin, N. (2006) Early Initiation of and Exclusive Breastfeeding in Large-Scale Community-Based Programmes in Bolivia and Madagascar. Journal of Health, Population and Nutrition, 4, 530-539.

[7] Edmond, K., Zandoh, C., Quigley, M., Amenga-Etego, S., Owusu-Agyei, S. and Kirkwood, B. (2006) Delayed Breastfeeding Initiation Increases Risk of Neonatal Mortality. Pediatrics, 117, e380-e386. https://doi.org/10.1542/peds.2005-1496

[8] Setegn, T., Gerbaba, M. and Belachew, T. (2011) Determinants of Timely Initiation of Breastfeeding among Mothers in Goba Woreda, South East Ethiopia: A Cross Sectional Study. BMC Public Health, 11, Article No. 217.

https://doi.org/10.1186/1471-2458-11-217

[9] Girard, L., Cote, S., De Lauzon-Guillain, B., Dubois, L., Falissard, B. and Forhan, A. (2016) Factors Associated with Breastfeeding Initiation: A Comparison between France and French-Speaking Canada. PLoS ONE, 11, e0166946. https://doi.org/10.1371/journal.pone.0166946

[10] Kelishadi, R., Rashidian, A., Jari, M., Khosravi, A., Khabiri, R. and Elahi, E. (2016) A National Survey on the Pattern of Breastfeeding in Iranian Infants: The IrMIDHS Study. Medical Journal of the Islamic Republic of Iran, 30, 425.

[11] Bimerew, A., Teshome, M. and Kassa, G. (2016) Prevalence of Timely Breastfeeding Initiation and Associated Factors in Dembecha District, North West Ethiopia: A Cross-Sectional Study. International Breastfeeding Journal, 11, Article No. 28. 
https://doi.org/10.1186/s13006-016-0087-4

[12] MaJra, J. and ViJay, K. (2016) Barriers to Early Initiation and Continuation of Breastfeeding in a Tertiary Care Institute of Haryana: A Qualitative Study in Nursing Care Providers. Journal of Clinical and Diagnostic Research, 10, 16-20. https://doi.org/10.7860/JCDR/2016/19072.8559

[13] Sharma, K. and Byrne, A. (2016) Early Initiation of Breastfeeding: A Systematic Literature Review of Factors and Barriers in South Asia. International Breastfeeding Journal, 11, Article No. 17. https://doi.org/10.1186/s13006-016-0076-7

[14] Dzossa, A.D. and Tchamgoue, H. (2011) Santé de l'enfant. Dans Enquête Démographique et de Santé, et à Indicateurs Multiple (EDS-MICS). INS et ORC Macro, Calverton. http://www.statistics-cameroon.org/news.php?id=74

[15] Constance, A., Gewa, M., Monica, O. and Lauren, S. (2011) Determinants of Early Child-Feeding Practices among HIV-Infected and Non Infected Mothers in Rural Kenya. Journal of Human Lactation, 27, 239-249. https://doi.org/10.1177/0890334411403930

[16] ORC Macro (2004) Cameroon 2004, Nutrition of Young Children and Mothers. The DHS Program.

http://www.dhsprogram.com/publications/publication-ANC20-Africa-Nutrition-C hartbooks.cfm

[17] Institut National de la Statistique (INS) - Ministère de l'Economie, de la Planification et de l'Aménagement du Territoire (2011) Cameroun-Enquête Démographique et de Santé et l'Enquête par grappe à Indicateurs Multiples. https://dhsprogram.com/pubs/pdf/fr260/fr260.pdf

[18] Cameroun-Cinquième Enquête Démographique et de Santé au Cameroun (2018). https://dhsprogram.com/pubs/pdf/FR360/FR360.pdf

[19] Beilin, Y., Bodian, C., Weiser, J., Hossain, S., Arnold, I. and Feierman, D. (2005) Effect of Labor Epidural Analgesia with and without Fentanyl on Infant Breast-Feeding: A Prospective, Randomized, Double-Blind Study. Anesthesiology, 103, 1211-1217. https://doi.org/10.1097/00000542-200512000-00016

[20] Baumgarder, D., Muehl, P., Fischer, M. and Pribbenow, B. (2003) Effect of Labor Epidural Anesthesia on Breast-Feeding of Healthy Full-Term Newborns Delivered Vaginally. The Journal of the American Board of Family Practice, 16, 7-13. https://doi.org/10.3122/jabfm.16.1.7

[21] Odent, M. (2005) Césariennes: Questions, effets, enjeux. Alerte face à la banalisation. Le Souffle d'Or. Vol. 1. Barret-sur-Méouge: Elsevier Masson, 200 p.

[22] Hobbs, A.J., Mannion, C.A., McDonald, S.W., Brockway, M. and Tough, S.C. (2016) The Impact of Caesarean Section on Breastfeeding Initiation, Duration and Difficulties in the First Four Months Postpartum. BMC Pregnancy Childbirth, 16, Article No. 90. https://doi.org/10.1186/s12884-016-0876-1

[23] World Health Organization (2003) Global Strategy for Infant and Young Child Feeding. World Health Organization, Report No 14, Geneva. https://www.who.int/nutrition/topics/global_strategy/en/

[24] Barousseau, T. and Sharieff, G. (2006) Newborn Emergencies: The First 30 Days of Life. Pediatric Clinics of North America, 53, 69-84. https://doi.org/10.1016/j.pcl.2005.09.011

[25] Pineda, R.G. (2006) Breastfeeding Practices in the Neonatal Intensive Care Unit before and after an Intervention Plan. University of Florida, Gainesville, 99.

[26] Musa, S.A. (2014) Vaginal Delivery and Maternal Knowledge on correct Breast- 
feeding Initiation Time as Predictors of Early Breastfeeding Initiation: Lesson from a Community-Based Cross-Sectional Study. ISRN Epidemiology, 2014, 1-6.

[27] Hashimm, T.H, Mgongom, M., Katangam, J., Uriyom, J.G., Damianm, D.J., Stray-Pedersenm, B., et al. (2017) Predictors of Appropriate Breastfeeding knowledge among Pregnant Women in Moshi Urban, Tanzania: A Cross-Sectional Study. International Breastfeeding Journal, 12, Article No. 11.

https://doi.org/10.1186/s13006-017-0102-4

[28] Morhason-Bello, I.O., Adedokun, B.O. and Ojengbede, O.A. (2009) Social Support during Childbirth as a Catalyst for Early Breastfeeding Initiation for First-Time Nigerian mothers. International Breastfeeding Journal, 4, Article No. 16. https://doi.org/10.1186/1746-4358-4-16

[29] Edmond, K.M., Zandoh, C., Quigley, M.A., Amenga-Etego, S., Owusu-Agyei, S. and Kirkwood, B.R. (2006) Delayed Breastfeeding Initiation Increases Risk of Neonatal Mortality. Pediatrics, 117, e380-e386. https://doi.org/10.1542/peds.2005-1496

[30] WHO (2019) Support for Mothers to Initiate and Establish Breastfeeding after Childbirth. http://www.who.int/elena/titles/breastfeeding_support/en/ 


\section{Questionnaire}

\section{General information}

Patient's code

Date ..$/$

Date of birth: /................/

Phone number:

\section{S1. Maternal data}

\section{Sociodemographic data}

S1.Q1. Age (years) /

S1.Q2. Occupation: Housewife /_/ Civil servant/_/Student/_/ Others /_/

S1.Q3. Region of origin / Adamaoua/_ / Centre /_ / East/_/ Far North/_/ Littoral/_/ North/_/ North-West/_/South/_/ South-West/_ West/_/

S1.Q4. Level of education: Primary /_/ Secondary/_/ University/_/ Out-of-school I_I

Number of children: /

\section{S2. Delivery data}

S2.Q1. Delivery route or mode: vaginal/_/ caesarean section/_/

\section{S3. Feeding problems}

S3.Q1. Nipple anomalies: Yes /_/

$$
\text { No /_l }
$$

\section{S4. Newborn data}

S4.Q1. Gestational age at birth (if possible): /

S4.Q2. Hospitalization at birth: Yes /_ I

If yes, precise

\section{S4. Average time to initiate breast feeding (in minutes), and factors}

If the average time is greater than 60 minutes, ask the questions below:

S4.Q1. Why did you take more than one hour to start breastfeeding your baby? (open answer)

Ask others questions with regards to the answer given by the mother

S4.Q2. What about the health care provider? Did they give you information about the average time to initiate breastfeeding after delivery? If yes, what did they say? (open answer)

S4.Q3. According to you and according to the doctors or health care providers, how was your baby's general state after birth?

S4.Q4. Was the baby able suck?

S4.Q5. Have you observed any belief concerning breastfeeding? 